[Agr. Biol. Chem., Vol, 30, No. 5, p. 506 510, 1966]

\title{
Fatty Acid Composition of Hydrocarbon-Assimilating Yeast
}

\author{
By Masayuki Mizuno, Yukiji Shimojima, Takashi Iguchi, Isao TAKeda \\ and Saburo SENOH
}

Research Laboratory, Asahi Chemical Industry Co., Ltd.

Received December 1, 1965

\begin{abstract}
As a part of extensive program on microbial utilization of hydrocarbons, lipid components of Candida petrophillum SD-14 grown on n-alkanes and glucose as carbon sources were studied. In any carbon source, cellular fatty acids of the yeast contained palmitic, palmitoleic, stearic, oleic and linoleic acids as major components.

When $n$-tridecane was fed to the yeast, fatty acids with odd- and even-number of carbon atoms were produced in almost identical quantity. Another yeast, Torulopsis petrophillum SD-77, also gave a very similar fatty acid pattern by $n$-tridecane substrate. These phenomena indicate the existence of $\mathrm{C}_{2}$ addition and $\beta$-oxidation of the fatty acid formed in the yeasts.

In the cases of $n$-tridecane, $n$-hexadecane and glucose as substrate, about a half of SD-14's lipid was phospholipid, which consisted of phosphatidyl ethanolamine and phosphatidyl choline principally. Free alcohol and wax were not detected in any case.
\end{abstract}

\section{INTRODUCTION}

Although many kinds of hydrocarbonoclastic microorganisms have been reported, very little investigation of cellular lipid component of these microbes has been made. ${ }^{1}$ Consequently, an investigation of the lipids of these organisms would give useful informations in metabolic and physiological studies of microbial oxidation of hydrocarbons.

Recently, fatty acid composition of glycerides and waxes of $n$-alkane-grown nocardia, and accumulation of a co-polymer of $\beta$-hydroxybutyric and $\beta$-hydroxybutenoic acids from $n$-butane by the same strain have been reported. $^{2.31}$

As a part of extensive program on microbial utilization of hydrocarbons, cellular lipid components of yeasts were investigated under various conditions. Results of pseudomonas grown on hydrocarbons will be shown elsewhere.

\footnotetext{
1) R. L. Raymond and J. B. Davis, Appl. Microbiol, , 8, 329 (1960).

2) J. B. Davis, ibid, 12, 210 (1964).

3) J. B. Davis, ibid., 12, 301 (1964).
}

\section{MATERIALS AND METHODS}

Organisms. Both Candida petrophillum SD-14 and Torulopsis petrophillum SD-77 were isolated from the soil and characterized by the method of Lodder and Kreger-van Rij.")

Culture method. The yeasts were inoculated into a medium containing $1 \mathrm{~g}$ of beef extract, $1 \mathrm{~g}$ of polypeptone, $1 \mathrm{~g}$ of glucose, and $0.5 \mathrm{~g}$ of $\mathrm{NaCl}$ in $100 \mathrm{ml}$ of distilled water $\left(\mathrm{pH} \mathrm{5)}\right.$, and shaken at $30^{\circ} \mathrm{C}$. A two-day-old culture was transferred into a mineral solution, consisting of hydrocarbon $2 \mathrm{ml}$, urea $0.2 \mathrm{~g}$, ammonium sulfate $0.2 \mathrm{~g}, \mathrm{KH}_{2} \mathrm{PO}_{4} 0.15 \mathrm{~g}, \mathrm{Na}_{2} \mathrm{HPO}_{4}$ $0.3 \mathrm{~g}, \mathrm{MgSO}_{4} 7 \mathrm{H}_{2} \mathrm{O} 0.005 \mathrm{~g}, \mathrm{FeSO}_{4} \cdot 7 \mathrm{H}_{2} \mathrm{O} 0.001 \mathrm{~g}$, and yeast extract (Difco) $0.1 \mathrm{~g}$ in $100 \mathrm{ml}$ of distilled water ( $\mathrm{pH} 5$ ), and incubated with continuous shaking at $30^{\circ} \mathrm{C}$. After an incubation for 3 days, the cells were harvested, washed twice with distilled water and then freeze-dried. In the case of glucose as a carbon source, the cells were harvested after incubation for 48 hours with nutrient medium.

Hydrocarbons. All the hydrocarbons $\left(\mathrm{C}_{9}, \mathrm{C}_{10}, \mathrm{C}_{13}\right.$, $\mathrm{C}_{16}, \mathrm{C}_{18}$; over $98 \%$ in purity, $\mathrm{C}_{11}, \mathrm{C}_{12}, \mathrm{C}_{14} ; 95 \%$ in purity) used here were purchased from Tokyo Kasei Chemicals, with the exception of $n$-pentadecane and $n$ -

4) J. Lodder and N. J. W. Kreger-Van Rij, "The Yeasts" North-Holland, Amsterdam, 1952. 
heptadecane (both $98 \%$ in purity, Kanto Koatsu Chemicals). They were used without further purification.

Extraction and purification of lipid. Lipid fraction was extracted from dried cells with a mixture of chloroform-methanol (1:1, v/v) by Pedersen's method, ${ }^{5}$ ) and purified with distilled water without intermediate drying by the method of Folch et al.6) Purified lipid was evaporated to dryness in vacuo under nitrogen stream at $40^{\circ} \mathrm{C}$.

Analytical methods. Iodine number was estimated by Wijs' method. Nitrogen content was determined by Dumas' method, and phosphorus content by Allen's method.7) Ethanolamine was estimated by the method of Wheeldon and Collins, ${ }^{8}$ choline by Kushner's method, 9) and sterol by that of LiebermannBurchard.

Preparation of fatty acid methyl esters. Lipids or lipid fractions were refluxed with alcoholic potassium hydroxide, and liberated fatty acids were methylated by refluxing in methanolic solution of $0.5 \mathrm{~N}-\mathrm{HCl}$.

Gas chromatography. Fatty acid methyl esters were analyzed with a model GC-2B (Shimadzu, Kyoto) using polyester succinate as liquid phase. The column was $300 \mathrm{~cm}$ in length, $3 \mathrm{~mm}$ i.d., and operated at $210^{\circ} \mathrm{C}$ under the helium flow rate of $30 \mathrm{ml}$ per minute. Fatty acid composition was calculated from the weights of the peaks on the charts.

Silicic acid chromatography. Activation of silicic acid (Kanto Kagaku Chemicals, over 100 mesh for chromatography) and chromatography was carried out by the method of Hirsch and Ahrens.10) Triglyceride fractions were rechromatographed on Amberlite IRA400 column to separate free fatty acids.

Thin-layer chromatography. Neutral lipids were chromatographed on Kieselgel $\mathrm{H}$ (Merck) plate dried at $100^{\circ} \mathrm{C}$ for 1 hour. For the analysis of phospholipids, a basic plate was used.

Following solvent systems were used.

1. n-hexane-diethyl ether-acetic acid $(99: 1: 1, v / v)$

2. n-hexane-diethyl ether-acetic acid $(92: 8: 1, \mathrm{v} / \mathrm{v})$

3. 1,2-dichloroethane-acetic acid (100:1, v/v)

4. chloroform-methanol-water $(65: 25: 4, v / v)$ The spots were detected by spraying with the de-

5) T. A. Pedersen. Acta Chem. Scand.. 16, 374 (1962).

6) J. Folch, M. Lees and G. H. Sloane Starley, J. Biol. Chem., 226, 497 (1957).

7) R. J. L. Allen, Biochem. J., 34, 858 (1940).

8) L.W. Wheeldon and F.D. Collins, ibid., 66, 435 (1957).

9) D. K. Kushner, Biochim. Biophys. Acta, 20, 554 (1956).

10) J. Hirsch and E.H. Ahrens, J. Biol Chem.. 233, 311 (1958). velopers such as 40\% sulfuric acid, Dragendorff's reagent or ninhydrin reagent followed by plate heating, or the spots were developed by plate preheating followed by spraying with $5 \%$ phosphomolybdic acid.

\section{RESULTS AND DISCUSSION}

Yeast SD-14, Candida soil isolate, was grown in different hydrocarbons as a carbon source. Relationship between hydrocarbons administered and yeast yield is given in Table $\mathrm{I}$. Results shows that $\mathrm{C}_{14}$ to $\mathrm{C}_{17} n$-alkanes are most assimilable for the yeast.

Tkble I. Cellular Yield of Candida petrophillum SD-14 FROM VARIOUS CARBON SOURCES

$\begin{array}{cc}\text { Carbon source } & \text { Yeast yield } \\ n-\mathrm{Alkanes} & \mathrm{mg} / 100 \mathrm{ml} \\ \mathrm{C}_{9} & 32.7 \\ \mathrm{C}_{10} & 37.0 \\ \mathrm{C}_{11} & 541.3 \\ \mathrm{C}_{12} & 776.3 \\ \mathrm{C}_{13} & 802.2 \\ \mathrm{C}_{14} & 1001.9 \\ \mathrm{C}_{15} & 1132.4 \\ \mathrm{C}_{16} & 1127.1 \\ \mathrm{C}_{17} & 1130.0 \\ \mathrm{C}_{18} & 905.7 \\ \text { Glucose } & 844.0\end{array}$

In preliminary experiment, cellular fatty acids of the yeast grown on various hydrocarbons (each $3 \mathrm{ml}$ per $100 \mathrm{ml}$ of medium) were directly extracted as their methyl esters by the method of Abel et al., ${ }^{11}$ and gas chromatographically analyzed. They gave almost identical gas chromatographic patterns and contained palmitic, palmitoleic, stearic, oleic and linoleic acids as major components, in any $n$-alkane with even-number of carbon atoms.

On the contrary, fatty acid fraction of $n$ tridecane-grown yeast SD-14 showed a very characteristic pattern. For identification of each peak, the fatty acid methyl esters, prepared from purified lipid, were catalytically hydrogenated in the presence of platinum

11) K. Abei, H. deSchmertzing and J.I. Peterson, J. Bacteriol., 85,1039 (1963). 


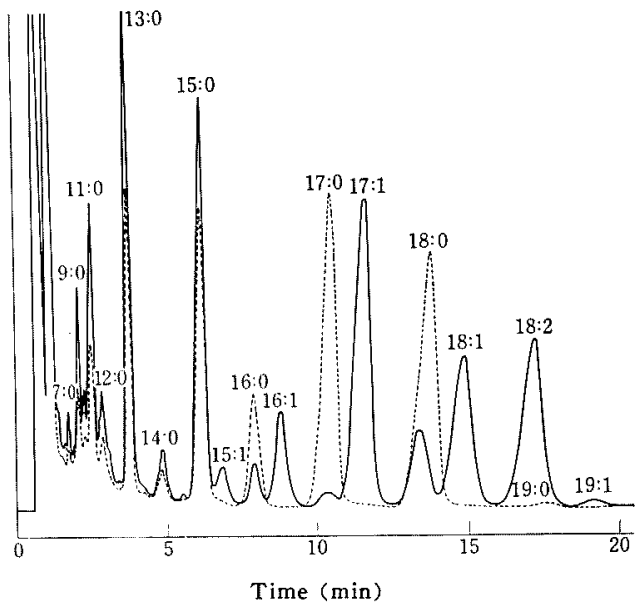

FIG. 1. Change in Gas Chromatogram of Cellular Fatty Acids of Candida petrophillum SD-14 Grown on $n$-Tridecane before and after Catalytic Hydrogenation.

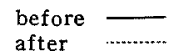

oxide. Before and after hydrogenation, the gas chromatograms were compared and the components were tentatively identified as shown in Fig. 1. The fraction contains relatively large amount of fatty acids with the odd-numbered carbon atoms.

This phenomenon was also observed with another yeast SD-77, Torulopsis soil isolate. The fatty acids of this organism grown on $n$-tridecadene and $n$-hexadecane showed gas chromatographic patterns closely resembled with those of SD-14's.

In accordance with hydrocarbon utilization by the yeasts and physiological significance of acids with odd-numbered carbons, detailed analysis of the lipid components was carried out. As carbon sources, $n$-tridecane, $n$-hexadecane and glucose were chosen, and each cellular lipid of SD-14 was extracted and purified. In the case of $n$-tridecane, the concentration of the hydrocarbon was reduced to $1.5 \mathrm{ml}$ in $100 \mathrm{ml}$ of medium to establish the complete consumption of the substrate.
TABLe II. Lipid Content of Candida petrophillum SD-14 Grown IN DifFERENT Carbon SOURCes, AND GHARACTERISTICS OF THE LIPIDS

$\begin{array}{lccccc}\quad \begin{array}{c}\text { Carbon } \\ \text { source }\end{array} & \text { Lipid } & \begin{array}{c}\text { lodine } \\ \text { number }\end{array} & \begin{array}{c}\text { Acid } \\ \text { value }\end{array} & \mathrm{P} & \mathrm{N} \\ & \% & & & \% & \% \\ n \text {-Tridecane } & 7.3 & 92 & 6.6 & 1.20 & 1.65 \\ n \text {-Hexadecane } & 8.9 & 75 & 6.3 & 1.72 & 1.40 \\ \text { Glucose } & 3.5 & 101 & 5.1 & 2.03 & 0.88\end{array}$

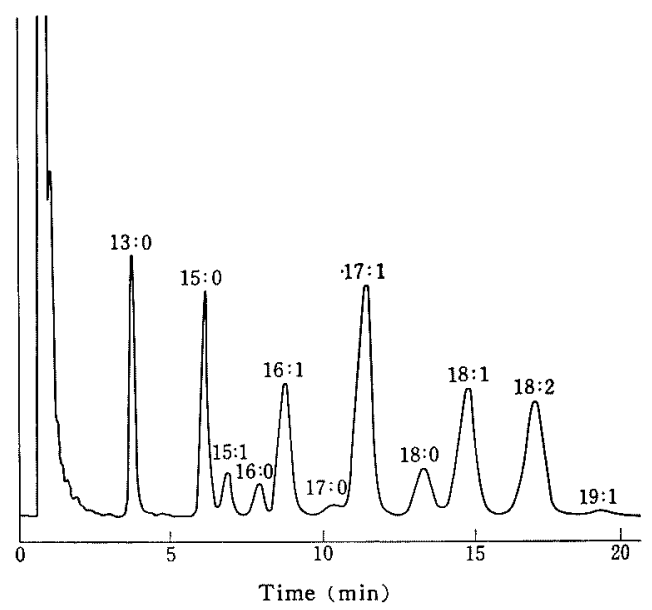

FIG. 2. Gas Chromatogram of Cellular Fatty Acids of Torulopsis petrophillum SD-77 Grown on nTridecane.

Lipid content and their characteristic are shown in Table II.

The purified lipids were chromatographed on silicic acid column by the stepwise elution of neutral lipids with diethyl ether in petroleum ether, followed by the elution of phospholipids with methanol. Triglyceride fractions were rechromatographed on Amberlite IRA-400 column to separate contaminating free fatty acids. Each fraction was partly identified by thin-layer chromatography, and results obtained were shown in Table III. Free alcohol and wax were not detected in any case.

In each case, about a half of lipids was phospholipids, which contained phosphatidyl ethanolamine and phosphatidyl choline as major components in addition to a small 
TABLE III. CoMposition of THE LiPIDS OF Candida petrophillum SD-14 GROWN ON $n$-TRIDECANE, $n$ Hexadecane and Glucose as Carbon Sources

$\begin{array}{lrrl}\text { Component } & n-\mathrm{G}_{13} & n-\mathrm{C}_{16} & \text { Glucose } \\ \text { Triglyceride }(\%) & 4.4 & 9.1 & 6.8 \\ \text { Free fatty acid }(\%) & 17.3 & 12.7 & 4.5 \\ \text { Total sterol }(\%)^{*} & 7.2 & 4.6 & 4.3 \\ \text { Phospholipid }(\%) & 50.3 & 48.4 & 53.3 \\ \text { Phosphatidyl choline** } & 10 & 19 & 20 \\ \text { Phosphatidyl ethanolamine** } & 58 & 45 & 55 \\ \text { * as ergosterol } & & \\ \text { ** content based on the total phospholipids }\end{array}$

amount of phosphatidyl serine. Although the function and the metabolism of the phospholipids are not clarified yet, its physiological role might be closely related to hydrocarbon assimilation by the yeast. Triglyceride contents were low, and total sterol contents were rather high. The amounts of free fatty acids were rather high compared with the expected values from each acid value of the lipids, indicating partial decompositions of labile component(s) during chromatographic procedure. Changes in individual lipid components in the course of yeast growth have not been studied yet, but its investigation is expected to give useful informations about the role and function of phospholipid or lipid itself in hydrocarbonoclastic microorganisms.

Fatty acid compositions of the lipids, and of the lipid fractions separated by silicic acid chromatography were characterized gas-chromatographically (Table IV), however, partial distribution to a particular lipid component of fatty acids with odd or even number of carbon atoms was not observed. Moreover, each of the fractions gave relatively resembled fatty acid patterns. It is clear that both $\beta$ oxidation and $\mathrm{C}_{2}$ addition are operative, as shown in fatty acid pattern of the yeast SD-14 grown on $n$-tridecane, and the yeast is able to incorporate both odd- and evennumbered carbon chains without difference. However, Davis ${ }^{2)}$ reported that the fatty acid component of glycerides from $n-\mathrm{C}_{13}$ to $\mathrm{C}_{20}$ alkanes by the nocardia consisted of an oddor even-number of carbon atoms subject to the feature of the hydrocarbon substrate, and the predominating acids were invariably of the same chain length as the substrate, excepting the case of $\mathrm{C}_{20} n$-alkane. The yeast SD-14 grown on $n$-tridecane contained fatty acids of odd- and even-numbered carbons in almost equal amount, and the yeast produced

\section{TABLE IV. FATTY ACID Composition of Lipids AND Lipid CoMPONENTS of Candida petrophillum SD-14}

The results are expressed as per cent of total fatty acids of each lipid or lipid fraction.

\begin{tabular}{|c|c|c|c|c|c|c|c|c|c|c|c|c|}
\hline \multirow{2}{*}{$\begin{array}{l}\text { Fatty } \\
\text { acid }\end{array}$} & \multicolumn{4}{|c|}{$n-\mathrm{C}_{13}$} & \multicolumn{4}{|c|}{$n-\mathrm{C}_{16}$} & \multicolumn{4}{|c|}{ Glucose } \\
\hline & Total & PL* & $\mathrm{TG}^{*}$ & FFA* & Total & PL & $\mathrm{TG}$ & FFA & Total & PL & TG & FFA \\
\hline $12: 0 * *$ & & & & & & & & & 0.3 & 0.5 & & 2.2 \\
\hline $14: 0$ & & & 1.7 & 1.1 & & & 0.2 & 0.6 & 0.7 & 0.5 & 0.8 & 5.5 \\
\hline $15: 0$ & 9.3 & 4.7 & 2.6 & 3.2 & & & 0.3 & 1.7 & & & 0.8 & \\
\hline $15: 1$ & 0.6 & & & & & & & & & & & \\
\hline $16: 0$ & 6.1 & 9.3 & 17.2 & 4.2 & 19.2 & 11.0 & 15.9 & 14.4 & 8.6 & 11.4 & 5.0 & 16.8 \\
\hline $16: 1$ & 6.9 & 6.5 & 5.3 & 4.2 & 23.1 & 16.6 & 14.8 & 16.2 & 9.3 & 8.3 & 8.2 & $3 \cdot 4$ \\
\hline $17: 0$ & & & 0.9 & & & & & 0.4 & & & & \\
\hline $17: 1$ & 28.8 & 19.6 & 20.6 & 29.8 & & 1.4 & 1.7 & 4.6 & 1.4 & 1.3 & 2.1 & 13.4 \\
\hline $18: 0$ & & 1.9 & 3.8 & 4.2 & & & 7.1 & 6.9 & 0.6 & & 1.6 & \\
\hline $18: 1$ & 31.9 & 36.4 & 30.1 & 45.8 & 50.0 & 50.6 & 49.2 & 49.9 & 34.4 & 39.3 & 41.9 & 52.9 \\
\hline $18: 2$ & 16.3 & 21.5 & 16.3 & 6.3 & 7.7 & 20.4 & 10.8 & 5.1 & 44.8 & 38.8 & 39.6 & 5.7 \\
\hline $19: 1$ & & & 1.5 & 1.1 & & & & & & & & \\
\hline
\end{tabular}

* PL, TG and FFA indicate phospholipid, triglyceride and free fatty acid, respectively.

** The first number indicates chain length, the second indicates the number of double bond. 


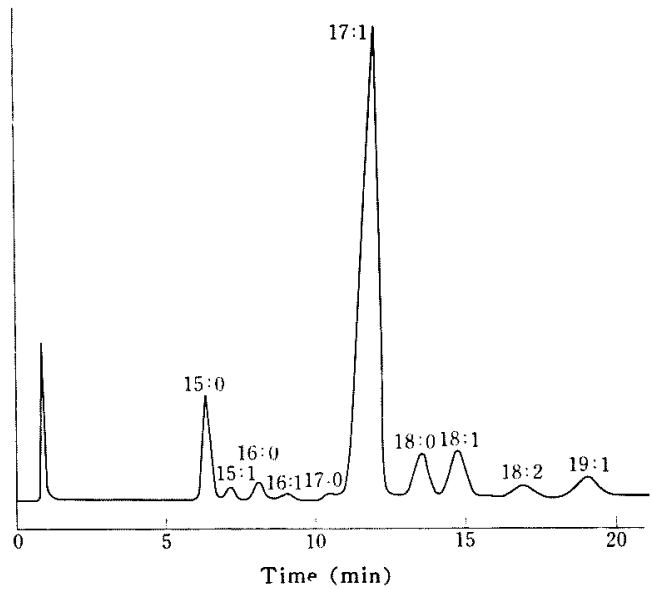

FIG. 3. Gas Chromatogram of Cellular Fatty Acids of Candida petrophillum SD-14 Grown on $n$-Pentadecane.

$n$-heptadecenoic acid as a major component ( $70 \sim 80 \%$ based on the total cellular fatty acid) from $n$-pentadecane and $n$-heptadecane as shown in Figs. 3 and 4 . In the case of $n$ tridecane substrate, fatty acids obtained at lower concentration of hydrocarbon showed a different chromatographic pattern from that obtained at higher concentration (cf. Fig. 1). It is natural that the cellular fatty acid composition will vary in the course of yeast growth. It appears, therefore, that study of the composition of cellular lipid components in different phases of growth is also

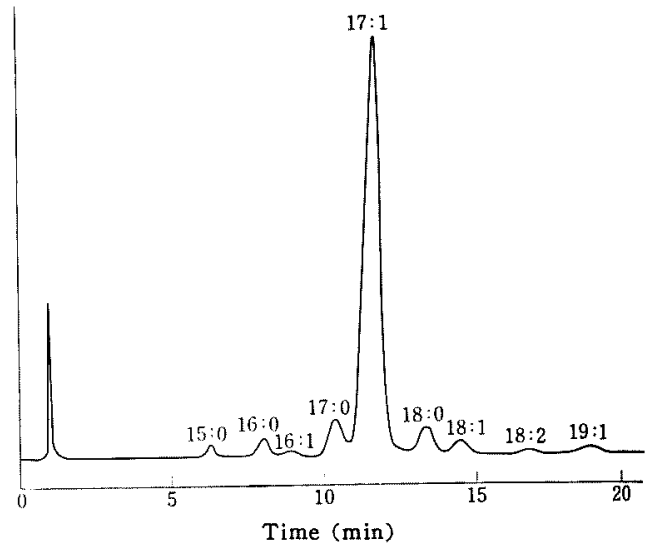

FIG. 4. Gas Chromatogram of Cellular Fatty Acids of Candida petrophillum SD-14 Grown on $n$-Heptadecane.

very interesting in accordance with the mechanism of hydrocarbon assimilation by the yeast.

Acknowledgement. The authors are much indebted to Professor M. Noda of Kyoto Prefectural University for his invaluable guidance and generous gift of fatty acids of odd-numbered carbon. The authors also wish to express their thanks to Director Dr. A. Suzuki and Dr. M. Murakoshi of their laboratory for the interest and encouragement during the course of this work. 